Research Article

\title{
Effect of TIPA on Chloride Immobilization in Cement-Fly Ash Paste
}

\author{
Baoguo Ma, Ting Zhang, Hongbo Tan $(D$, Xiaohai Liu, Junpeng Mei, Wenbin Jiang, \\ Huahui Qi, and Benqing Gu
}

\author{
State Key Laboratory of Silicate Materials for Architectures, Wuhan University of Technology, Wuhan 430070, China \\ Correspondence should be addressed to Hongbo Tan; thbwhut@whut.edu.cn
}

Received 27 January 2018; Accepted 26 April 2018; Published 16 July 2018

Academic Editor: Cristina Leonelli

Copyright (C) 2018 Baoguo Ma et al. This is an open access article distributed under the Creative Commons Attribution License, which permits unrestricted use, distribution, and reproduction in any medium, provided the original work is properly cited.

\begin{abstract}
Utilization of sea sands and coral aggregate for concrete in ocean construction is increasingly attracting the attention all over the world. However, the potential risk of steel corrosion resulting from chloride in these raw materials was one of the most concerned problems. To take this risk into account, chloride transporting to the surface of steel should be hindered. The formation of Friedel's salt in hydration process is widely accepted as an effective manner for this hindrance. In this study, an attempt to hasten the formation of Friedel's salt by adding triisopropanolamine (TIPA) was done in the cement-fly ash system, with intention to chemical bind chloride, and the chloride-binding capacity at $60 \mathrm{~d}$ age was examined. The results show that TIPA can enhance the chloride-binding capacity of cement-fly ash paste at $60 \mathrm{~d}$ age, and the reason is that the formation of Friedel's salt can be accelerated with addition of TIPA. The mechanism behind is revealed as follows: on the one hand, the accelerated cement hydration provides more amount of calcium hydroxide to induce the pozzolanic reaction of fly ash, which can hasten the dissolution of aluminum into liquid phase; on the other hand, TIPA can directly hasten the dissolution of aluminum in fly ash, offering more amounts of aluminum in liquid phase. In this case, the aluminum/sulfate $(\mathrm{Al} / \mathrm{S})$ ratio was obviously increased, benefiting the formation of Friedel's salt in hydration products. Such results would expect to provide useful experience to promote the chloride-binding capacity of cement-fly ash system.
\end{abstract}

\section{Introduction}

In recent years, marine exploitation is increasingly attracting the attention all over the world. In ocean construction, the durability of concrete is of great importance $[1,2]$. However, attempt to utilize the sea sands and coral aggregate as raw materials of concrete has been done, and the potential risk of steel corrosion is one of the most concerned problems in terms of durability. In fact, this risk depends on whether the chloride could transport to the surface of the steel or not. Therefore, binding the chloride to hinder its transport would be of great importance to the durability of reinforced concrete [3-5].

There are two forms of chloride ions in ocean aggregates. One is free chloride, which means that this kind of chloride can transport around in concrete, and the other is bound chloride. The former would lead to the corrosion of reinforcing steel if the chloride is transported to the surface of steel, while the latter has almost no risk of steel corrosion. Therefore, binding free chloride would significantly reduce the risk of steel corrosion, with great benefit to the durability of concrete structures. According to the binding mechanism, chemical reactions and physical absorption can be found in the literatures [6-8]. The former means that chloride ions can participate in the hydration reaction to form the hydration products, such as Friedel's salt $\left(\mathrm{FS}, 3 \mathrm{CaO} \cdot \mathrm{Al}_{2} \mathrm{O}_{3} \cdot \mathrm{CaCl}_{2} \cdot 10 \mathrm{H}_{2} \mathrm{O}\right)$ and Kuzel's salt (KS, $\left.3 \mathrm{CaO} \cdot \mathrm{Al}_{2} \mathrm{O}_{3} \cdot 0.5 \mathrm{CaCl}_{2} \cdot 0.5 \mathrm{CaSO}_{4} \cdot 10 \mathrm{H}_{2} \mathrm{O}\right)$ $[9,10]$. The latter is that chloride ions are mainly absorbed by calcium silicate hydrate (C-S-H) gel [11-13]. By contrast, the former is more effective and plays the dominant role. Furthermore, binding chloride by formation of FS and KS depends on the reaction of aluminum ions, sulfate ions, chloride ions, and calcium ions [14]. Generally, more amounts of the aluminum phase in the cement system can lead to more 
TABle 1: Chemical compositions of cement and FA.

\begin{tabular}{lccccccccc}
\hline & Loss & $\mathrm{SiO}_{2}$ & $\mathrm{Al}_{2} \mathrm{O}_{3}$ & $\mathrm{Fe}_{2} \mathrm{O}_{3}$ & $\mathrm{SO}_{3}$ & $\mathrm{CaO}$ & $\mathrm{MgO}_{2}$ & $\mathrm{~K}_{2} \mathrm{O}$ & $\mathrm{Na}_{2} \mathrm{O}$ \\
\hline Cement (wt.\%) & 3.82 & 24.08 & 4.72 & 2.46 & 2.31 & 58.24 & 1.95 & 1.02 & 0.27 \\
FA (wt.\%) & 5.97 & 48.33 & 31.69 & 4.14 & 1.37 & 4.12 & 0.50 & 1.34 & 0.37 \\
\hline
\end{tabular}

amounts of formation of FS. Taking $\mathrm{C}_{3} \mathrm{~A}$, for example, cement with higher content of $\mathrm{C}_{3} \mathrm{~A}$ can obviously increase the content of FS in hydration products [15-17]. Addition of supplementary cementitious materials, such as fly ash (FA), can also hasten the formation of FS because aluminum can be dissolved in the process of pozzolanic reaction [18-20].

In the cement-FA system, chemicals can also hasten the pozzolanic reaction of FA and dissolution of aluminum. Paya et al. showed that grinding fly ash to finer particles can obviously hasten the hydration of fly ash, but this method will lead to energy consumption [21]. Dakhane et al. reported that $\mathrm{pH}$-neutral alkali sulfates could activate fly ash, resulting in $70 \%$ reduction of clinker factor [22]. Sodium sulfate can also activate the pozzolanic reaction of fly ash, but this kind of chemical has negative effect on long-term performance of cement-based materials [23]. By contrast, TIPA can exert high efficiency to hasten the dissolution of FA and cement minerals [24-27]. On the one hand, the accelerated hydration of cement can form more calcium hydroxide $(\mathrm{CH})$ to hasten the pozzolanic reaction of FA; on the other hand, TIPA can also induce the dissolution of FA to release more amounts of silicate and aluminum into solution to participate in the hydration. In this case, with addition of TIPA in the cement-FA system, pozzolanic reaction of $\mathrm{FA}$ and dissolution of aluminum would be accelerated and the amount of FS would be expected to increase, with great contribution to chloride-binding capacity.

In this study, the chloride-binding capacity of the cement-FA system with addition of TIPA was systemically studied. The free chloride was induced with addition of sodium chloride $(\mathrm{NaCl})$, and the chloride-binding capacity of the paste cured for $60 \mathrm{~d}$ was examined. Hydration process of the system was investigated with analysis of hydration heat, and the hydration products were characterized with scanning electron microscope (SEM), thermogravimetric analysis (TGA), and X-ray diffraction (XRD). The reaction degree of cement and FA was evaluated with solid-state nuclear magnetic resonance (NMR). The dissolution of FA was analyzed with SEM and inductively coupled plasma (ICP) emission spectrometer. The mechanism behind was investigated in terms of hydration heat, hydration products, and dissolution of FA. Such results were expected to provide useful experience to promote the chloride-binding capacity of the cement-FA system.

\section{Materials and Test Methods}

\subsection{Materials}

2.1.1. Cement and Fly Ash. Portland cement (P.I 42.5, Wuhan Yadong Cement Co., Ltd.) in accordance with the requirements of GB175-2007 (Chinese Standard) and class F-II FA in accordance with the requirements of $\mathrm{GB} / \mathrm{T}$ 1596-2005 (Chinese Standard) were used in this study.

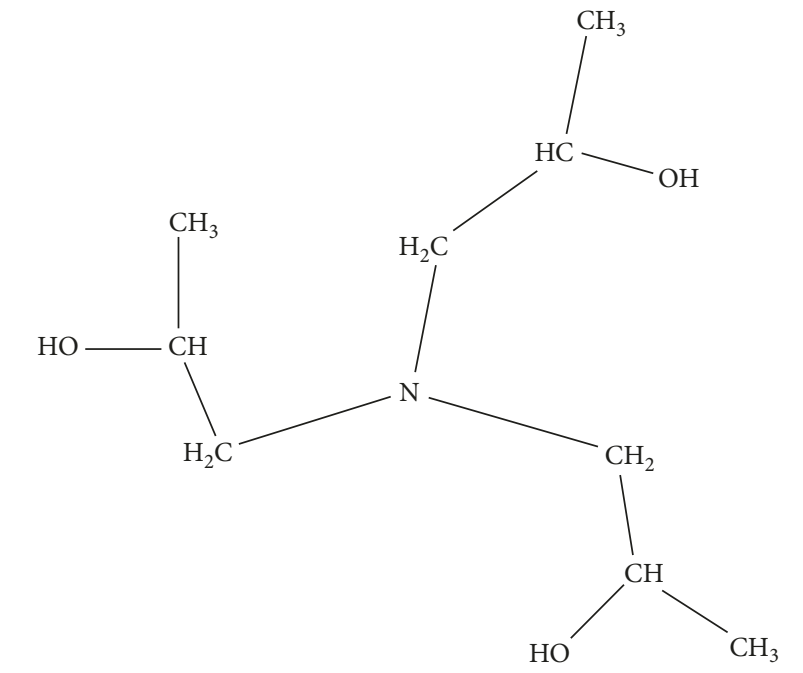

FIGURE 1: Schematic diagram of molecular structure of TIPA.

The chemical compositions of cement and FA were analyzed by XRF, and the results are given in Table 1.

2.1.2. TIPA. A reagent-grade triisopropanolamine (TIPA, anhydrous white solid, $\geq 95 \%$ purity, made by Aladdin Biochemical Technology Co., Ltd., Shanghai, China) was used. Additionally, the added dosage of TIPA was recorded as the solid amount. The chemical structure of TIPA is show in Figure 1.

2.1.3. Preparation of Specimens. Cement-FA paste (30\% FA and $70 \%$ cement) with addition of $\mathrm{NaCl}(1.11 \%$ of cement-FA binder) and TIPA $(0 \%, 0.03 \%, 0.06 \%$, and $0.10 \%$ of cementFA binder) was prepared with a water/binder ratio of 0.38 . TIPA and $\mathrm{NaCl}$ were dissolved in water in advance. The fresh pastes were cast in $40 \mathrm{~mm} \times 40 \mathrm{~mm} \times 40 \mathrm{~mm}$ cubic metallic moulds, cured in a $>90 \% \mathrm{RH}$ and $20 \pm 1^{\circ} \mathrm{C}$ chamber for $24 \mathrm{~h}$, and then demoulded and further cured with the same condition. At the age of 60 days, compressive strength was measured. The samples were also broken into small pieces and immediately immersed into ethanol in order to stop hydration. The pieces were dried in a vacuum drier at $60^{\circ} \mathrm{C}$. The samples were prepared for the measurement of chloridebinding capacity. Additionally, these specimens were also powdered by hand, and the powder, which could pass through a $63 \mu \mathrm{m}$ sieve, was prepared for the phase analysis (i.e., hydration products).

\subsection{Test Methods}

2.2.1. Chloride-Binding Capacity. The sample (about $20 \mathrm{~g}$ ) was dried in a vacuum drier at a temperature of $60 \pm 5^{\circ} \mathrm{C}$ for 
2 hours and then powdered by hand. The powder, which could pass through a $15 \mu \mathrm{m}$ sieve, was prepared for the measurement. The sample $(10 \mathrm{~g})$ was put into a triangular flask and distilled water $(100 \mathrm{~g})$ was added, and then it was oscillated violently for 1-2 min. The sample was soaked for 24 hours and then filtered. The filtrate $(20 \mathrm{~g})$ was put into triangular flask. Two drops of phenolphthalein were added as a $\mathrm{pH}$ indicator, and then it was neutralized with dilute sulfuric acid to be colorless. After that, 10 drops of potassium chromate indicator with a concentration of $5 \%$ were added, and silver nitrate $(0.02 \mathrm{~mol} / \mathrm{L})$ was added continuously until brick red precipitate appears. At this time, the added volume of silver nitrate solution was marked [28].

The amount of free chloride ion can be calculated as follows:

$$
P=\frac{C V_{3} \times 0.03545}{\left(G \times V_{2} / V_{1}\right)} \times 100 \%,
$$

where $P$ is the content of free chloride ions in paste, \%; $C$ is the concentration of $\mathrm{AgNO}_{3}, \mathrm{~mol} / \mathrm{L} ; G$ is the weight of the paste sample, $\mathrm{g}$; $V_{1}$ is the volume of water used to soak the sample, $\mathrm{mL} ; V_{2}$ is the volume of filtrate used for measurement, $\mathrm{mL}$; and $V_{3}$ is the volume of consumption of silver nitrate solution, $\mathrm{mL}$.

The initial content of chloride ions $\left(P_{0}\right)$ in the sample could be calculated by the added amount of $\mathrm{NaCl}$, and the chloride-binding rate (CBR) was calculated as follows:

$$
\mathrm{CBR}=\frac{\left(P_{0}-P\right)}{P_{0}} \times 100 \% .
$$

2.2.2. Compressive Strength. Three specimens of each mixture were tested, in accordance with GB/T50081-2002, and the average was the result of compressive strength.

2.2.3. Ions Dissolution of FA. Firstly, pore solution with different concentrations of TIPA $(0-20 \mathrm{~g} / \mathrm{L})$ was prepared with $\mathrm{KOH}$ and $\mathrm{NaOH}\left(\mathrm{K}^{+} / \mathrm{Na}^{+}=1: 1 ; \mathrm{pH}=13\right)$. One gram of $\mathrm{FA}$ was added into these solutions $(20 \mathrm{~g})$, respectively, and then mixed. The suspension was sealed in a plastic container and cured at a temperature of $20 \pm 1^{\circ} \mathrm{C}$. For each $12 \mathrm{~h}$, the containers were shocked in order to make the suspension to be even.

At the age of $60 \mathrm{~d}$, the suspension was centrifuged at $3600 \mathrm{r} / \mathrm{min}$ for 10 minutes in a centrifuge, and the content of $\mathrm{Al}, \mathrm{Fe}$, and $\mathrm{Si}$ in supernatant solution was tested with inductively coupled plasma (ICP, Optima 4300 DV, made by Perkin Elmer Ltd., USA) emission spectrometer. Based on these results, the effect of TIPA on the dissolution of FA was investigated.

In addition, the solid was dried in a vacuum drier with the temperature of $60 \pm 5^{\circ} \mathrm{C}$, and then the surficial morphology of the FA was characterized with field emission scanning electron microscope (SEM).

2.2.4. Hydration Heat. TIPA (0-0.10 wt.\% of cement-FA binder) and $\mathrm{NaCl}$ (1.11 wt.\% of cement-FA binder) were added into water in advance, and then the solution and cement-FA (30\% FA and 70\% cement) were mixed together with a water/binder ratio of 0.5 . Hydration heat was obtained with an isothermal calorimetry (TAM AIR, C80, SETARAM, France).

2.2.5. Phase Analysis. The effect of TIPA on hydration products was investigated with scanning electron microscope (SEM), thermogravimetric analysis (TGA), solid-state nuclear magnetic resonance (NMR), and X-ray diffraction (XRD).

(1) XRD. XRD data were collected with an X-ray diffractometer (XRD, D/Max- $\mathrm{RB})(\mathrm{Cu} \mathrm{K} \alpha$ radiation) at room temperature $\left(2 \theta=5-70^{\circ}\right.$, step $0.03^{\circ}$ with $3 \mathrm{~s} /$ point $)$.

(2) SEM. Field emission scanning electron microscope (FESEM, QUANTA FEG 450, FEI Co, USA) was used for SEM microstructural characterization.

(3) TG-DTG. TGA was conducted with the comprehensive thermal analyzer (German-resistant STA449F3). The heating rate was $10^{\circ} \mathrm{C} / \mathrm{min}$, using nitrogen as purging gas, and the temperature ranged from the room temperature to $1000^{\circ} \mathrm{C}$. $\mathrm{CH}$ was decomposed at the temperature ranging from 400 to $500^{\circ} \mathrm{C}$, and calcium carbonate resulting from the carbonation of $\mathrm{CH}$ in the process of preparing the samples was decomposed at $500-750^{\circ} \mathrm{C}$, as shown in the following equation [23]:

$$
\begin{aligned}
\mathrm{Ca}(\mathrm{OH})_{2} & \longrightarrow \mathrm{CaO}+\mathrm{H}_{2} \mathrm{O} \\
\mathrm{CaCO}_{3} & \longrightarrow \mathrm{CaO}+\mathrm{CO}_{2}
\end{aligned}
$$

The total content of $\mathrm{CH}$ in hydration products can be calculated as follow:

$$
M_{\mathrm{Ca}(\mathrm{OH})_{2}}=\frac{74 \times M_{\mathrm{H}_{2} \mathrm{O}}}{18}+\frac{74 \times M_{\mathrm{CO}_{2}}}{44} .
$$

where $M_{\mathrm{Ca}(\mathrm{OH})_{2}}$ : the mass of calcium hydroxide; $M_{\mathrm{H}_{2} \mathrm{O}}$ : at $400-500^{\circ} \mathrm{C}$, the weight loss resulting from water; and $M_{\mathrm{CO}_{2}}$ : at $500-750^{\circ} \mathrm{C}$, the weight loss resulting from carbon dioxide.

Additionally, the weight loss at the temperature range from 50 to $200^{\circ} \mathrm{C}$, due to evaporation of free water, dehydration of C-S-H gel, decomposition of ettringite (AFt), and dehydration of FS, is of great interest. To be more precise, the first peak at the low temperature is related to the evaporation of free water and dehydration of C-S-H gel, and the second peak with higher temperature is involved in evaporation of free water, dehydration of C-S-H gel, and decomposition of AFt; the third one is about dehydration of FS [29]. Such results can provide supplementary evidence to illustrate the effect of TIPA on the formation of FS.

(4) NMR. To further verify the effect of TIPA on hydration of cement-FA paste, the hydration products were characterized with ${ }^{29}$ Si MAS NMR. As reported in the literatures [30], six peaks can be found in NMR spectrum of hydrated cementFA paste; $Q^{1}$ (chain-end groups), $Q^{2}$ (middle-chain groups), and $Q^{2}(1 \mathrm{Al})$ (middle-chain groups where one of the adjacent tetrahedral sites is occupied by $\mathrm{Al}^{3+}$ ) represent the Si-O tetrahedron in hydration products; and $Q^{0}$ represents 
the $\mathrm{Si}-\mathrm{O}$ tetrahedron in unhydrated cement minerals, and $Q^{3}$ and $Q^{4}$ represent the $\mathrm{Si}-\mathrm{O}$ tetrahedron in FA. Due to different chemical surroundings of $\mathrm{Si}$ sites in cementitious materials, the polymerization degree of $\mathrm{Si}-\mathrm{O}$ tetrahedron and $\mathrm{Al} / \mathrm{Si}$ ratios in $\mathrm{C}-\mathrm{S}-\mathrm{H}$ can be evaluated.

${ }^{29} \mathrm{Si}-\mathrm{NMR}$ (solid-state nuclear magnetic resonance) was conducted with a Bruker Advance III400 spectrometer operating at $79.5 \mathrm{MHz}$. The rotation frequency was $5 \mathrm{kHz}$ and the delay time was $10 \mathrm{~s}$. Tetramethylsilane was used as a standard for ${ }^{29} \mathrm{Si}$. The data were processed with commercial solid-state NMR software package. It was firstly fitted, and then the phasing and baseline were corrected, followed by subsequently iterative fitting. During the deconvolution of ${ }^{29} \mathrm{Si}-\mathrm{NMR}$ spectra, the peak shapes were constrained with the Gaussian function. The main chain length (MCL) of C-S-H gel and the ratio of $\mathrm{Si}$ in $\mathrm{C}-\mathrm{S}-\mathrm{H}$ substituted by $\mathrm{Al}$ were calculated as follows [31]:

$$
\begin{aligned}
\mathrm{MCL} & =\frac{\left\{2 I\left(\mathrm{Q}^{1}\right)+2 I\left(\mathrm{Q}^{2}\right)+3 I\left[\mathrm{Q}^{2}(\mathrm{Al})\right]\right\}}{\mathrm{Q}^{1}}, \\
\frac{\mathrm{Al}}{\mathrm{Si}} & =\frac{0.5 I\left[\mathrm{Q}^{2}(\mathrm{Al})\right]}{\left\{I\left(\mathrm{Q}^{1}\right)+I\left(\mathrm{Q}^{2}\right)+I\left[\mathrm{Q}^{2}(\mathrm{Al})\right]\right\}} .
\end{aligned}
$$
follows:

Reaction degree of FA and cement was also calculated as

$$
\begin{aligned}
A_{\mathrm{FA}}(\%) & =\frac{1-I\left(Q^{3}+Q^{4}\right)}{I_{0}\left(Q^{3}+Q^{4}\right)}, \\
A_{\mathrm{C}}(\%) & =\frac{1-I\left(Q^{0}\right)}{I_{0}\left(Q^{0}\right)},
\end{aligned}
$$

where $I\left(Q^{0}\right), I\left(Q^{1}\right), I\left(Q^{2}\right)$, and $I\left[Q^{2}(\mathrm{Al})\right]$ represent the integrated intensities of signals $Q^{0}, Q^{1}, Q^{2}$, and $Q^{2}(\mathrm{Al})$ in hydrated cement-FA paste, respectively; $I_{0}\left(Q^{0}\right), I_{0}\left(Q^{3}\right)$, and $I_{0}\left(Q^{4}\right)$ represent the integrated intensities of signals $Q^{0}, Q^{3}$, and $Q^{4}$ in unhydrated cement-FA mixture.

\section{Results and Discussion}

3.1. Chloride Solidification. The effect of TIPA on the CBR of cement-FA paste cured for 60 days was examined, and the results are shown in Figure 2. As can be seen from the figure, in comparison with the reference (i.e., without TIPA), CBR at the age of 60 days is increased with addition of TIPA; with the dosage of $0.06 \%$, CBR reaches $48.40 \%$, with an increase of $11.1 \%$; when the dosage is further increased to $0.10 \%, \mathrm{CBR}$ increases to $53.47 \%$, with an increase of $22.8 \%$.

The binding of chlorine ions in the cement-FA system can be divided into chemical binding and physical adsorption. It can be inferred that addition of TIPA probably hastens the hydration of cement-FA system. On the one hand, the addition of TIPA can accelerate the dissolution of the ferric phase in cement minerals, which in most cases exists on the surface of the mineral particles due to the lower melting point. Accordingly, the dissolution of other phase can also be hastened, resulting in formation of more amount

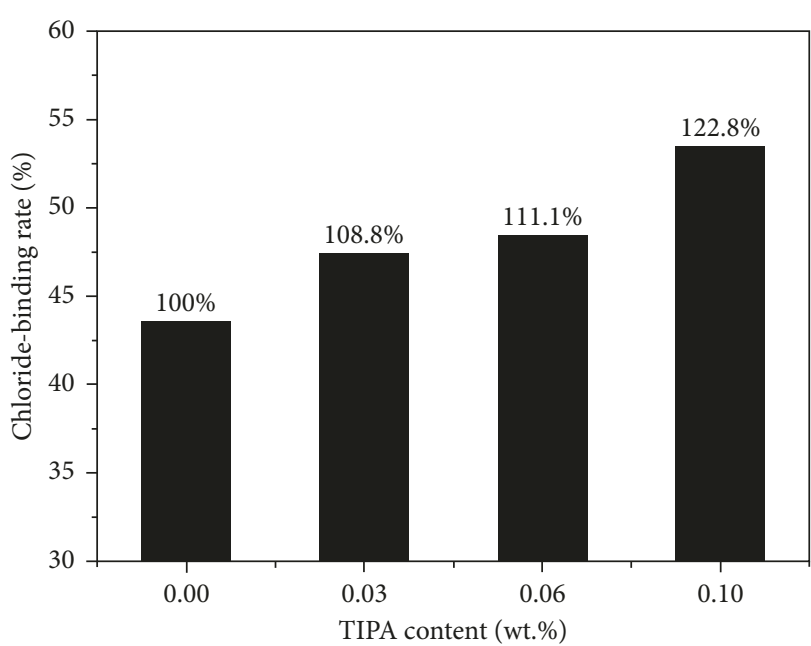

FIgURE 2: Effect of TIPA on the chloride-binding rate of $60 \mathrm{~d}$.

of $\mathrm{CH}$, which can induce the pozzolanic reaction of FA [32]. On the other hand, the addition of TIPA can also hasten the dissolution of FA, and in this case, the more amounts of aluminum would exist in the liquid phase and participate in hydration. Most likely more amounts of FS or KS could be formed [33].

Additionally, physical adsorption of chloride resulting from C-S-H gel can also contribute to chloride immobilization. With addition of TIPA, formation of C-S-H gel can be promoted, and more amount of C-S-H gel can exert stronger ability to adsorb and wrap chloride ions.

Based on discussion above, the improvement in CBR of the cement-FA system with addition of TIPA at $60 \mathrm{~d}$ age is closely related to the hydration of the system and the formation of FS and KS, which would be further illustrated in the following text.

3.2. Analysis of Hydration Products. To verify the contribution of FS or KS to CBR, the hydration products were characterized with XRD, TG, and SEM.

3.2.1. XRD. Cement-FA paste hydrated for 60 days with addition of TIPA $(0.06 \%)$ was discussed with XRD, and the results are shown in Figure 3. As can be seen from the figure, the peaks of $\mathrm{CH}$, AFm, AFt, and FS can be observed obviously. By contrast, the addition of TIPA increases the peak intensity of AFt and FS and reduces the intensity of AFm. This result indicates that TIPA can hasten the formation of AFt and FS at $60 \mathrm{~d}$ age.

3.2.2. TG-DTG. The mass loss curve of the sample is shown in Figure 4(a). As it can be seen from the TGA curve, the mass loss at the temperature range from 0 to $400^{\circ} \mathrm{C}$ is related to the loss of free water, decomposition of $\mathrm{C}-\mathrm{S}-\mathrm{H}$ gel, hydrated calcium sulphoaluminate and FS; that for $400-500^{\circ} \mathrm{C}$ is involved in the decomposition of $\mathrm{CH}$; and that for $500-750^{\circ} \mathrm{C}$ is due to the decomposition of carbon 


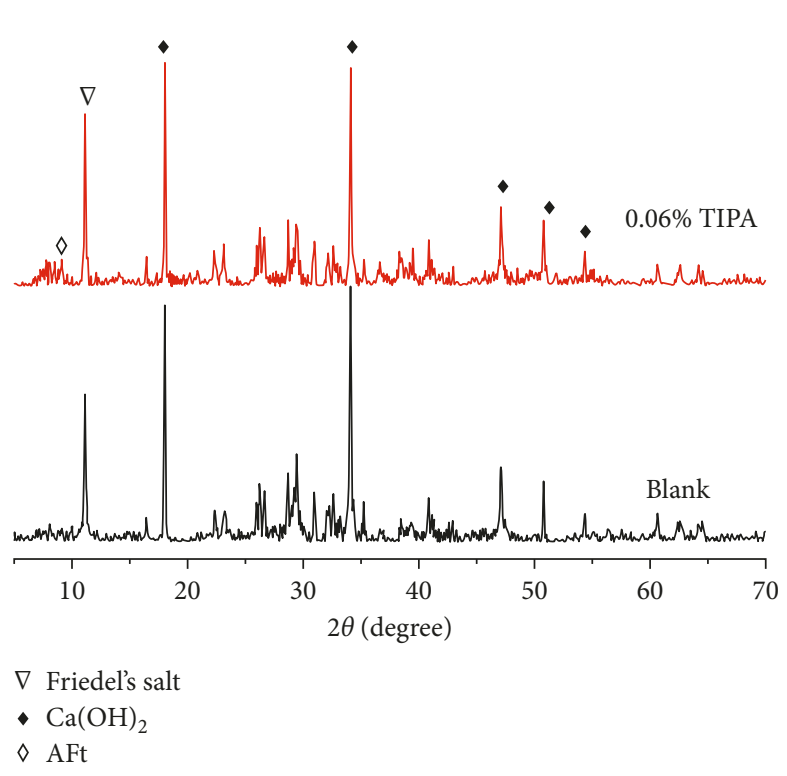

(a)

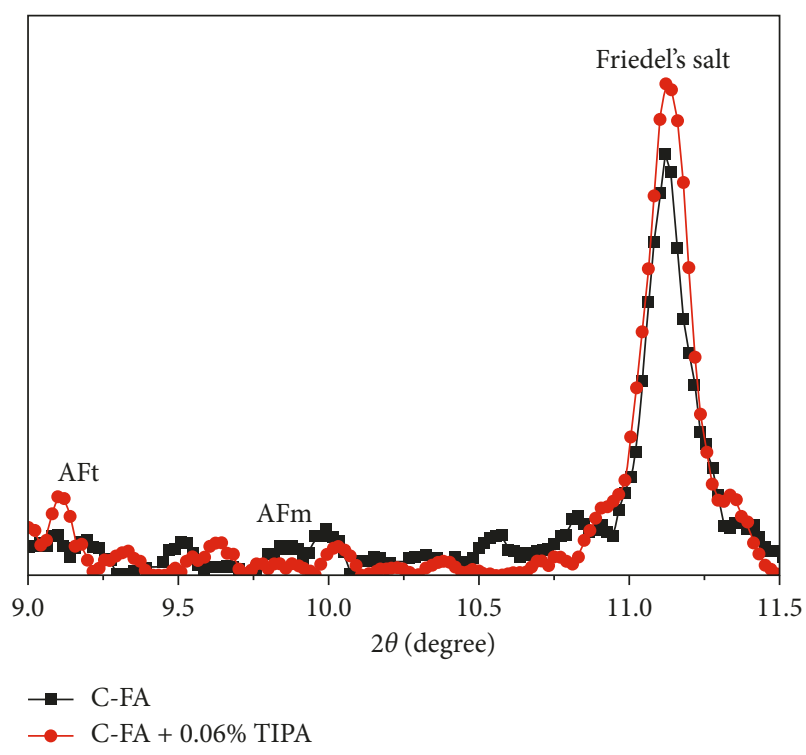

(b)

FIGURE 3: XRD patterns of cement-FA paste hydrated at 60 days.

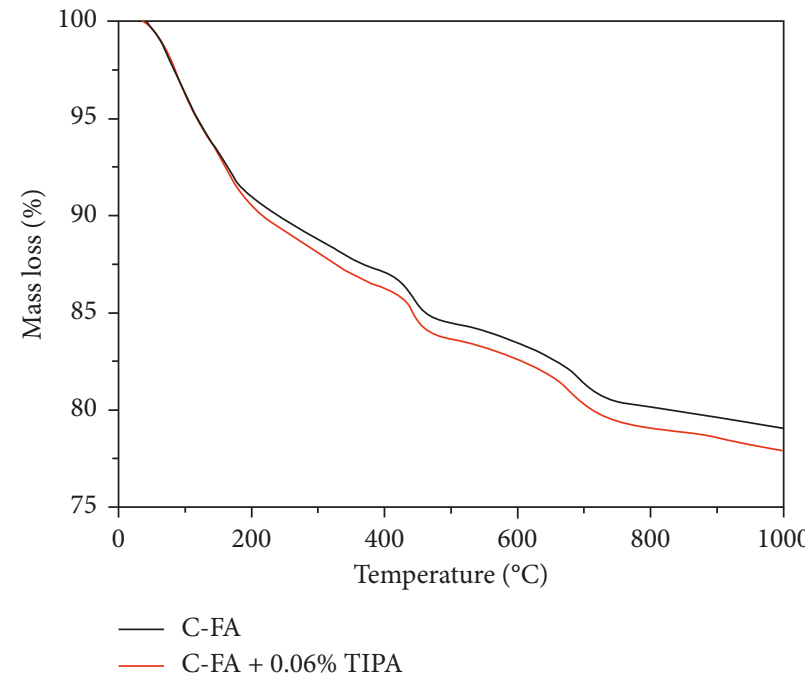

(a)

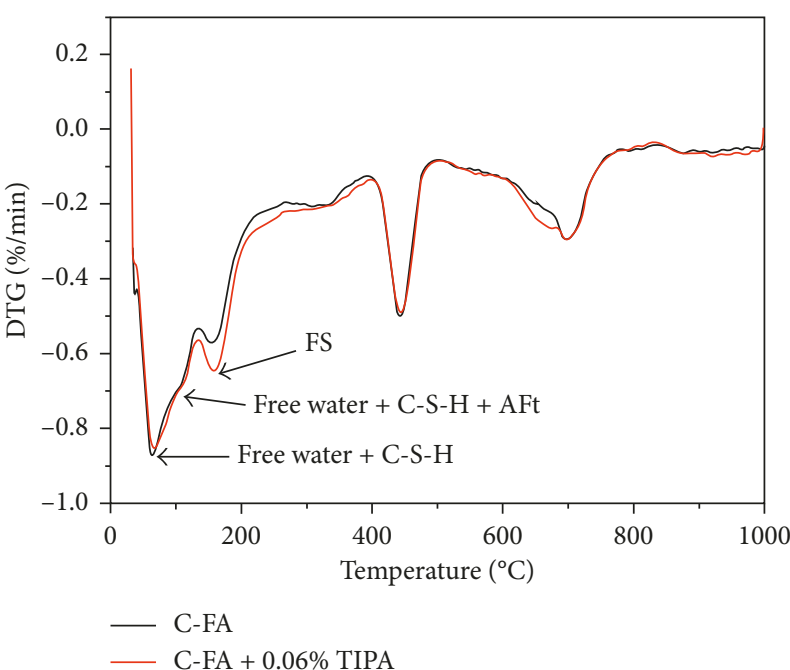

(b)

Figure 4: TG-DTG curve of the paste hydrated for $60 \mathrm{~d}$. (a) TG; (b) DTG.

dioxide which was formed in the process of preparing for the samples [34].

The weight loss at the temperature from 50 to $200^{\circ} \mathrm{C}$, mainly resulting from evaporation of free water and the decomposition of hydrate (C-S-H gel, AFt and FS), shows great interest. As reported in the literatures [35], FS would be decomposed at the temperature range of about $160^{\circ} \mathrm{C}$. It is noticed that in Figure 4(b), the absorption peak, resulting from decomposition of FS, is obviously increased with addition of TIPA $(0.06 \%)$, indicating more amount of FS. This result provides supplementary evidence to prove that TIPA can facilitate formation of FS, in agreement with the XRD results.
TABle 2: Calcium hydroxide content in the cement-FA system (wt.\%).

\begin{tabular}{lcc}
\hline Temperature range $\left({ }^{\circ} \mathrm{C}\right)$ & Blank & $0.06 \%$ TIPA \\
\hline $400-500^{\circ} \mathrm{C}$ & 2.66 & 2.55 \\
$500-750^{\circ} \mathrm{C}$ & 4.14 & 4.29 \\
$\mathrm{CH}$ content & 17.89 & 17.69 \\
\hline
\end{tabular}

However, the amount of $\mathrm{CH}$ in hydration products attracts more interest. As shown in Table 2, for $60 \mathrm{~d}$ age, the amount of $\mathrm{CH}$ in blank (without TIPA) is greater than that with addition of TIPA. This result indicates that TIPA can 


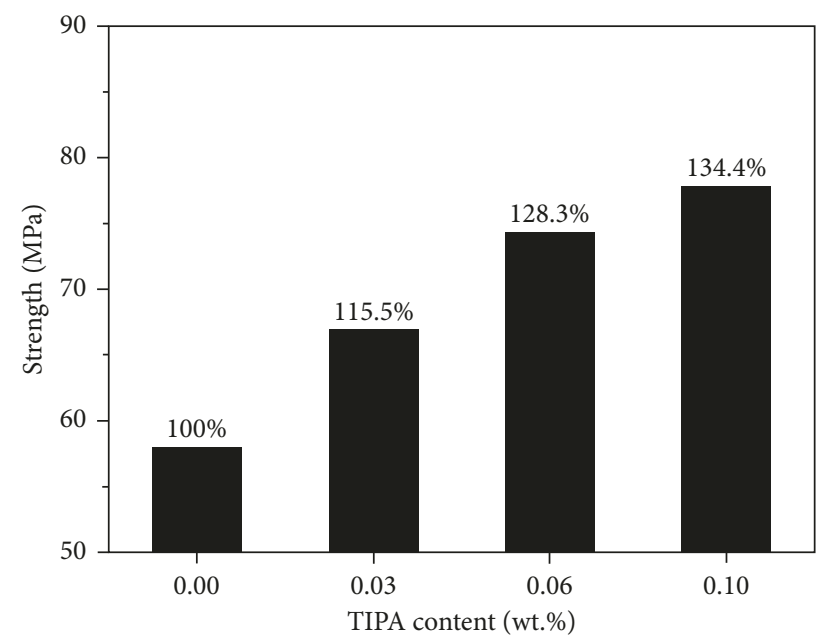

FIgURE 5: Effect of TIPA on compressive strength of $60 \mathrm{~d}$.

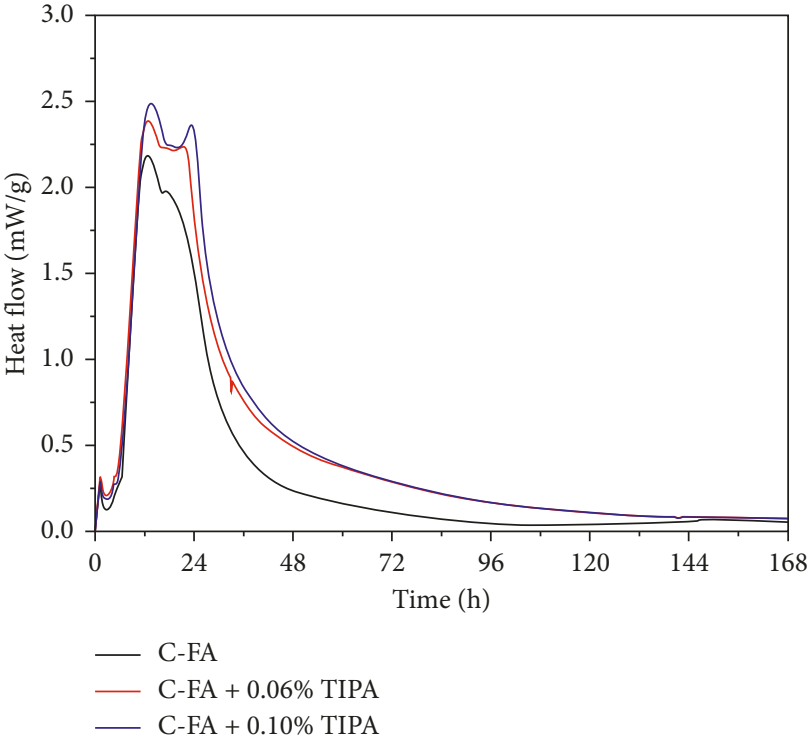

(a)

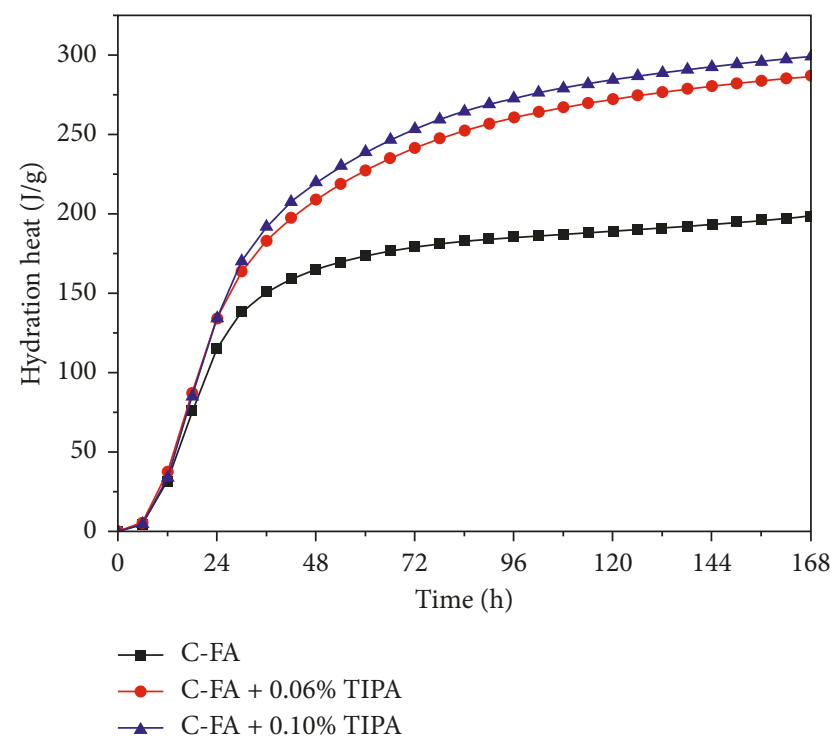

(b)

Figure 6: Hydration heat of cement-FA paste with TIPA. (a) Heat flow; (b) hydration heat.

reduce the amount of $\mathrm{CH}$ in hydration products at $60 \mathrm{~d}$ age. The amount of $\mathrm{CH}$ depends on the cement hydration and pozzolanic reaction of FA. Greater degree of cement hydration would generate more amount of $\mathrm{CH}$, and greater degree of pozzolanic reaction of FA would consume more amount of $\mathrm{CH}$. In comparison with the blank, the predominant aspect would determine the relative amount of $\mathrm{CH}$. Obviously, the acceleration of the FA, namely, consumption of $\mathrm{CH}$, should be predominated. This implies that TIPA can significantly hasten the pozzolanic reaction of FA.

Based on discussion above, pozzolanic reaction of FA and formation of FS can be hastened with addition of TIPA, and the improvement in CBR is mainly because of the accelerated formation of FS in hydrates, which would be closely related to the hydration process.

\subsection{Hydration Process}

3.3.1. Compressive Strength. To further verify the effect of TIPA on hydration of cement-FA paste, the compressive strength was examined, and the results are shown in Figure 5. As can be seen from the figure, the compressive strength at the age of 60 days increases with the increasing dosage of TIPA. Compared with the sample without TIPA, $0.03 \%$ TIPA increases the strength by $15.5 \%$; with the dosage of $0.10 \%$, the strength reaches $77.8 \mathrm{MPa}$, with an increase by $34.4 \%$. The increased strength implies that TIPA can also accelerate the hydration of the cement-FA system.

3.3.2. Hydration Heat. As reported in the literatures, the hydration of cement-FA includes the initial reaction, 


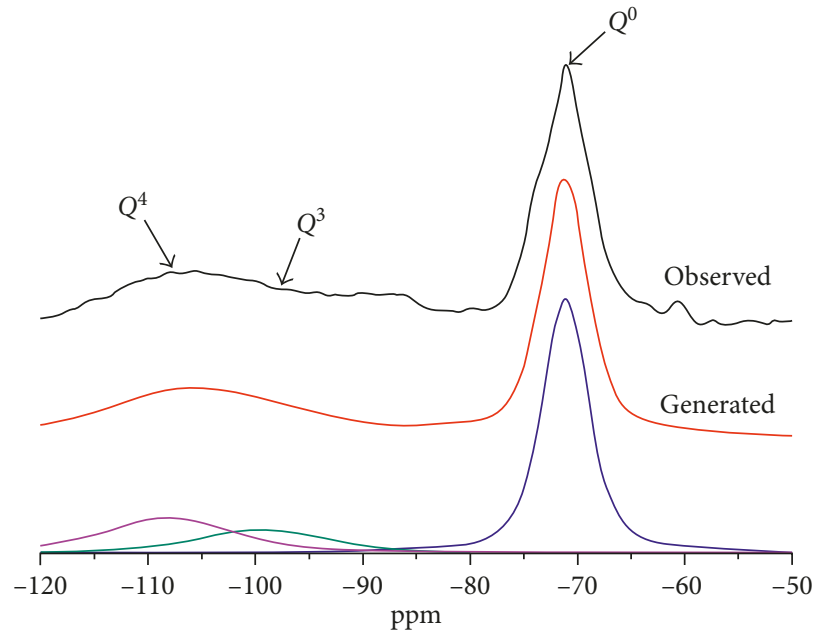

(a)

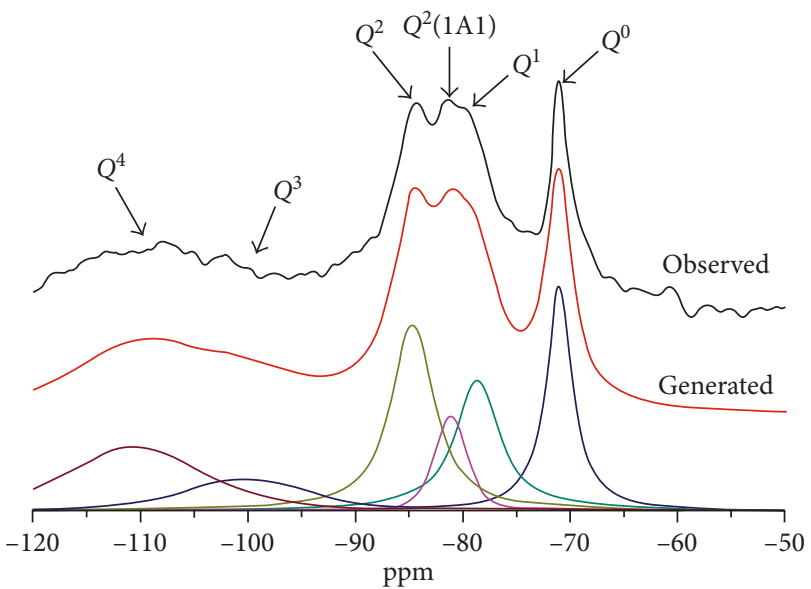

(b)

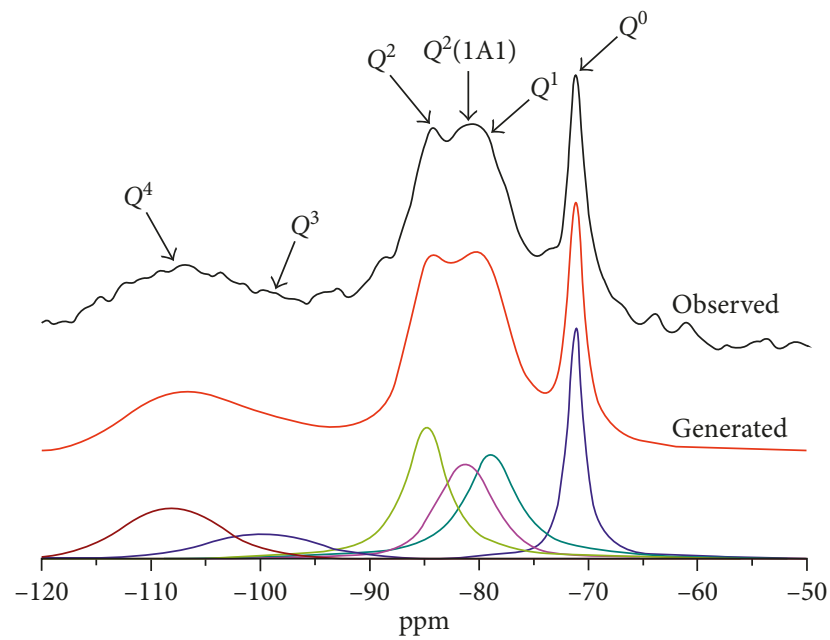

(c)

Figure 7: ${ }^{29}$ Si-NMR spectrum of cement-FA paste. (a) Unhydrated C-FA; (b) C-FA hydrated for $60 \mathrm{~d}$; (c) C-FA with $0.06 \%$ TIPA hydrated for 60 d.

a period of slow reaction, an acceleration period, and a deceleration period, as described by Taylor [36]. As shown in Figure 6(a), the addition of TIPA cannot change these four steps but can accelerate the release of hydration heat, indicating that TIPA can hasten the hydration of the cement-FA system. This can also be confirmed in Figure 6(b) that the cumulated heat is increased with addition of TIPA.

Furthermore, it is noticed that the extra peak at about $30 \mathrm{~h}$ can be seen clearly with addition of TIPA. As reported, the effect of TIPA on cement hydration can be divided into three phases: (1) adsorb on the surface of cement particles and slightly delay the hydration; (2) hasten the dissolution of ions, especially the ferric ion, to accelerate the formation of $\mathrm{AFt}$; and (3) facilitate the conversion of AFt to AFm [37, 38]. It can be inferred that the extra peak should be related to that conversion. The reason can be revealed that at the very beginning of the hydration, AFt should be formed because of the much faster dissolution speed of gypsum to provide enough sulfates, with lower $\mathrm{Al} / \mathrm{S}$ ratio. While with time going on, more amount of aluminum can increase the $\mathrm{Al} / \mathrm{S}$ ratio, resulting in conversion of AFt to AFm. In cement-FA paste with TIPA, the dissolution of aluminum in FA would be hastened, and the $\mathrm{Al} / \mathrm{S}$ ratio would be much higher than that without TIPA. In this case, the conversion of AFt to AFm can be facilitated:

$$
\begin{aligned}
& 3 \mathrm{CaO} \cdot \mathrm{Al}_{2} \mathrm{O}_{3} \cdot \mathrm{CaSO}_{4} \cdot 12 \mathrm{H}_{2} \mathrm{O}(\mathrm{AFm})+2 \mathrm{Cl}^{-} \longrightarrow \\
& 3 \mathrm{CaO} \cdot \mathrm{Al}_{2} \mathrm{O}_{3} \cdot \mathrm{CaCl}_{2} \cdot 10 \mathrm{H}_{2} \mathrm{O}(\mathrm{Fs})+\mathrm{SO}_{4}^{2-}+2 \mathrm{H}_{2} \mathrm{O}
\end{aligned}
$$

According to results in the literatures [14, 39], AFm can combine with chloride ions to form FS, and in cement-FA paste with TIPA, the conversion of AFt to AFm can be facilitated, which can further hasten the formation of FS.

3.3.3. ${ }^{29} \mathrm{Si}-\mathrm{NMR}$. The deconvoluted ${ }^{29} \mathrm{Si}$ MAS NMR spectra of the samples obtained from the fitting are plotted in Figure 7; reaction ratio, $\mathrm{MCL}$, and $\mathrm{Al} / \mathrm{Si}$ ratio were calculated, and the results are shown in Table 3. As shown in Figure 7, $Q^{0}, Q^{1}, Q^{2}(1 \mathrm{Al}), Q^{2}, Q^{3}$, and $Q^{4}$ can be seen clearly. In comparison with the unhydrated C-FA (as shown in Figure $7(\mathrm{a}))$, the increase in peak intensity of $Q^{1}, Q^{2}(1 \mathrm{Al})$, 
TABLE 3: Deconvolution results of the sample.

\begin{tabular}{lccccccccc}
\hline & $Q^{0}$ & $Q^{1}$ & $Q^{2}(1 \mathrm{Al})$ & $Q^{2}$ & $Q^{3}+Q^{4}$ & MCL & Al/Si & $\begin{array}{r}\text { Reaction ratio } \\
\text { of cement (\%) }\end{array}$ & $\begin{array}{c}\text { Reaction ratio } \\
\text { of fly ash (\%) }\end{array}$ \\
\hline Unhydrated C-FA & 62.27 & - & - & - & 37.73 & - & - & - & - \\
C-FA & 19.86 & 24.20 & 9.86 & 22.00 & 24.08 & 5.04 & 0.0879 & 68.11 & 36.18 \\
C-FA with 0.6\% TIPA & 16.00 & 21.77 & 18.00 & 22.34 & 21.89 & 6.53 & 0.1449 & 74.31 & 41.98 \\
\hline
\end{tabular}
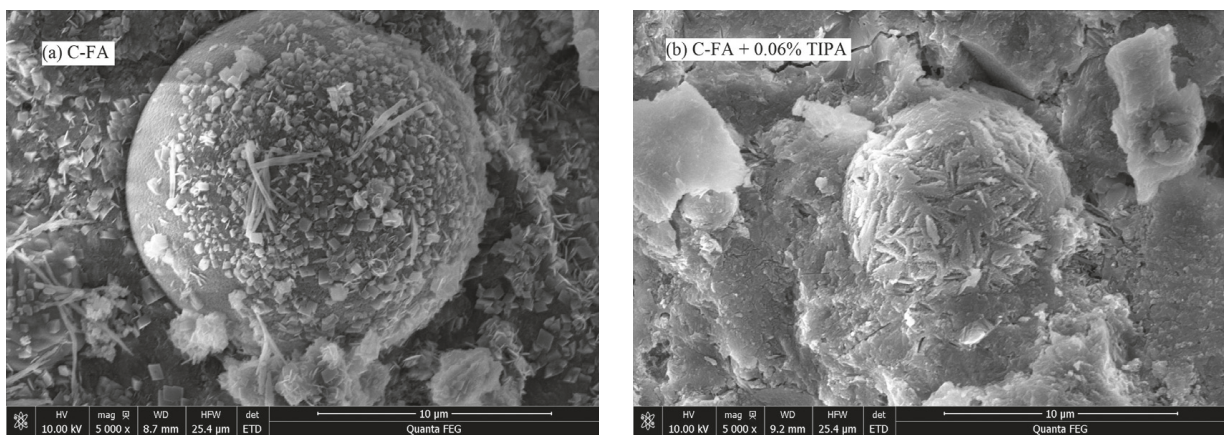

Figure 8: SEM images of the paste hydrated for $60 \mathrm{~d}$.

and $Q^{2}$ can be found, and the decline in $Q^{0}, Q^{3}$, and $Q^{4}$ can also be observed. These results illustrate the hydration of cement and the pozzolanic reaction of FA. More details can be found in Table 3: in comparison with the blank sample, $0.06 \%$ TIPA obviously reduces the amount of $Q^{0}$ and slightly declines the amount of $Q^{3}+Q^{4}$; this result demonstrates that TIPA can promote the cement hydration as well as the pozzolanic reaction of FA; by contrast, this promoting effect on cement hydration is much stronger than that of FA. Furthermore, C-FA has a MCL of 5.04, while that for C-FATIPA $(0.06 \%)$, it was 6.53 , which indicates that the addition of TIPA can increase the degree of silicate polymerization; this can also show that a higher degree of hydration has occurred. Moreover, the $\mathrm{Al} / \mathrm{Si}$ ratio is also increased with $0.06 \%$ TIPA, in comparison with blank paste (C-FA). This increase definitely confirms that the incorporation of TIPA into the cement-FA system induces the substitution of Si by $\mathrm{Al}\left(\mathrm{Al}^{[4]}\right)$ into $\mathrm{C}-\mathrm{S}-\mathrm{H}$, resulting in an increase in the length of silicate chain of C-S-H, in agreement with the results of MCL. Additionally, the reaction degree of cement without TIPA is $68.11 \%$, while that for addition of TIPA $(0.06 \%)$, it is $74.31 \%$, which indicates the accelerated hydration of cement by TIPA. The same results can also be found in FA: the reaction degree of FA is increased from $36.18 \%$ to $41.98 \%$ with $0.06 \%$ TIPA.

According to the analysis of NMR, the addition of TIPA not only hastens the hydration of cement but also accelerates the pozzolanic reaction of FA, and it also increases the degree of silicate polymerization, the length of $\mathrm{C}-\mathrm{S}-\mathrm{H}$, and substitution of $\mathrm{Si}$ by $\mathrm{Al}$, with contribution to the mechanical performance. This also hastens the dissolution of aluminum of FA into liquid phase.

3.3.4. SEM. Figure 8 shows the SEM images of the paste hydrated for $60 \mathrm{~d}$ in the presence and absence of TIPA.
As shown in Figure 8, more serious erosion can be seen clearly in Figure 8(b) than that in Figure 8(a), which implies that the addition of TIPA can hasten pozzolanic reaction of FA.

Based on the discussion of hydration heat, NMR, SEM, and compressive strength, it is concluded that TIPA can accelerate the pozzolanic reaction of FA and hydration of cement minerals at the age of $60 \mathrm{~d}$.

\subsection{Dissolution of Fly Ash}

3.4.1. Ions Dissolution. The accelerated hydration of FA by TIPA has been confirmed above, and the mechanism behind this is closely related to the dissolution of ions from FA into liquid. Accordingly, the reaction of FA in pore solution with various dosages of TIPA was investigated to further reveal the reason for the accelerated hydration of FA by TIPA.

The effect of TIPA on dissolution of FA in pore solution is shown in Figure 9. As shown in the figure, the dissolution of aluminum ions, ferric ions, and silicon ions was increased with the increasing dosage of TIPA, indicating that TIPA in pore solution can significantly hasten the dissolution of FA. TIPA $(20 \mathrm{~g} / \mathrm{L})$ can make the aluminum ions about 2.5 times and silicate ions about 2 times of the blank (without TIPA) at the age of 60 days. Furthermore, as shown in Figure 9(b), very little amount of Fe can be found without TIPA, which implies that ferric in FA is not that easy to be dissolved into pore solution in hydration process. However, with addition of TIPA, surprisingly, the dissolution of ferric ions was considerably hastened, in agreement with the results in the literatures [40, 41].

The morphology of FA was observed with SEM, as a supplementary evidence to prove the dissolution of ions of FA in pore solution. As shown in Figure 10(a), at the age of $60 \mathrm{~d}$, the erosion of FA in the pore solution can be seen clearly, and the amount of flocculent reaction products on 


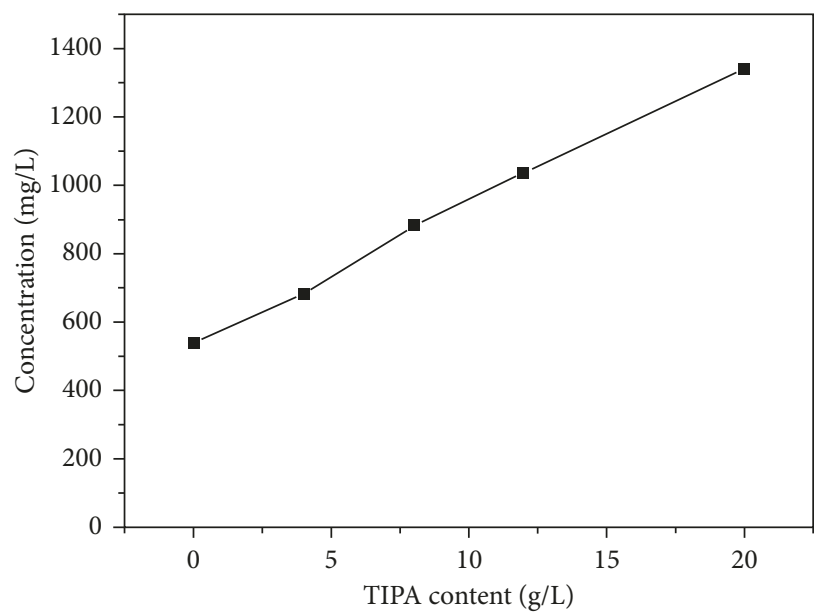

(a)

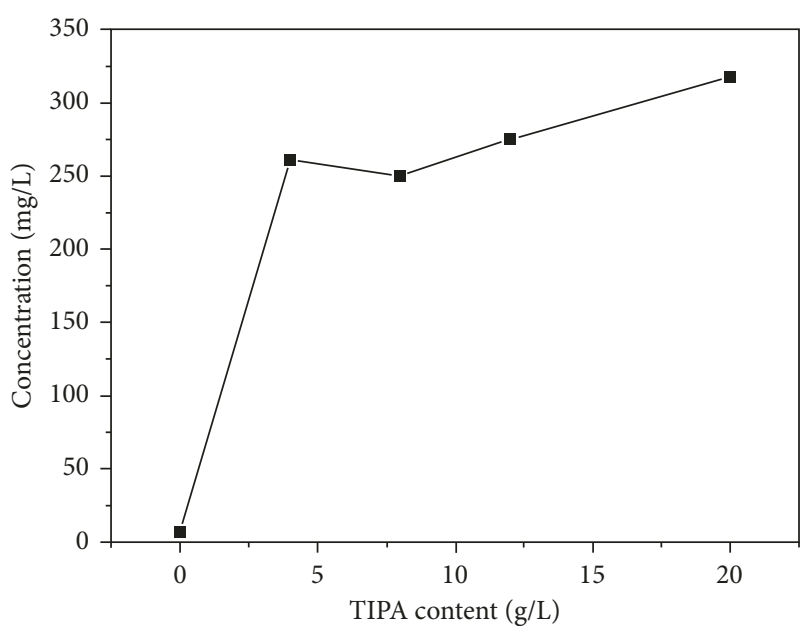

(b)

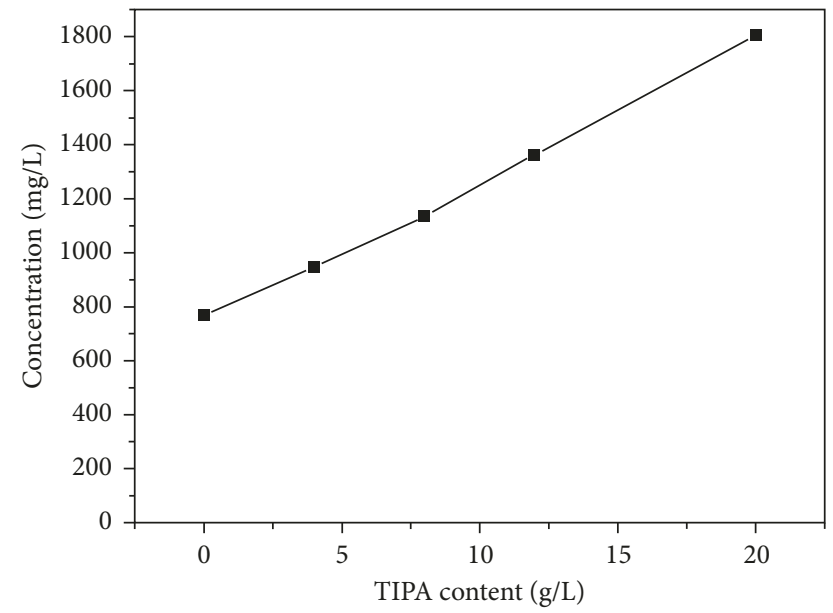

(c)

Figure 9: Ions dissolution of FA in the pore solution with TIPA at the age of 60 days. (a) Al; (b) Fe; (c) Si.
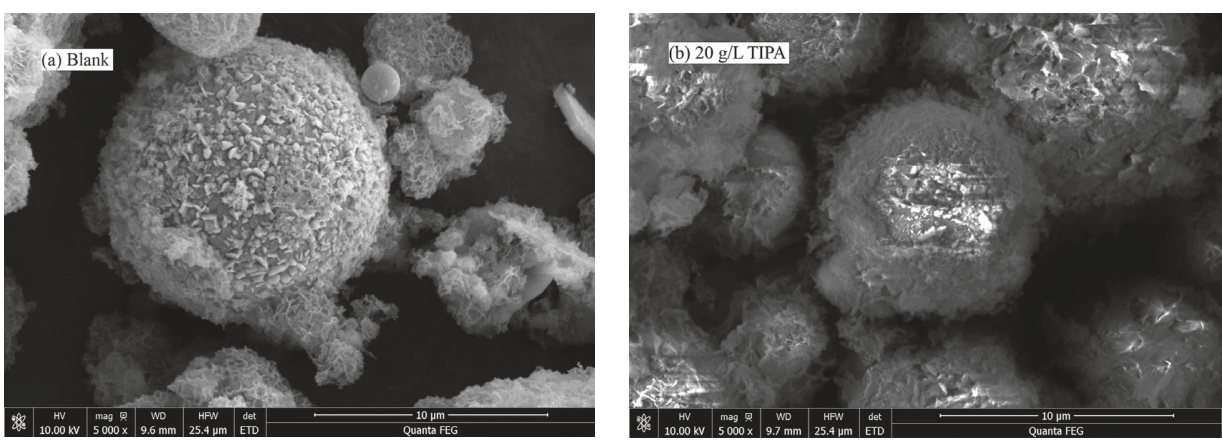

FIGURE 10: Morphology of FA immersed in pore solution for 60 days.

the surface can also be found. By contrast, as shown in Figure 10 (b), with TIPA solution $(20 \mathrm{~g} / \mathrm{L})$, the erosion of the surface is more seriously, indicating that dissolution of FA can be hastened at the age of $60 \mathrm{~d}$, in agreement with the results of ions dissolution.

Based on the discussion above, the promoted ions dissolution of FA into the liquid phase by addition of TIPA can be concluded, and this can benefit the improvement in CBR of the cement-FA system. The details for the reason can be summarized as follow:

On the one hand, the promotion of TIPA on cement hydration has been confirmed, which can generate more amount of $\mathrm{CH}$ to activate the pozzolanic reaction of FA, which means that the dissolution of FA can be hastened. On the other 
hand, the addition of TIPA can also accelerate dissolution of $\mathrm{Al}$ into the pore solution. As a result, the addition of TIPA can significantly accelerate the dissolution of FA into the liquid phase, especially the dissolution of aluminum. Furthermore, the aluminum dissolved from FA can participate in the formation of C-S-H gel as C-A-S-H gel and also increase the Al/S ratio to induce the formation of $\mathrm{AFm}$ from $\mathrm{AFt}$. AFm can react with chloride to form FS. Additionally, the excessive can also be directly reacted with calcium and chloride to generate FS. Consequently, the formation of FS can be hastened, and the CBR of the cement-FA system can be improved.

\section{Conclusion}

(1) Addition of TIPA in the cement-FA system can not only hasten the hydration of cement minerals but also accelerate the pozzolanic reaction of $\mathrm{FA}$, with contribution to the mechanical performance.

(2) The FS can also be accelerated with addition of TIPA at the age of $60 \mathrm{~d}$, which is responsible for the improved chloride-binding capacity of the system.

(3) Dissolution of aluminum, silicate, and ferric in FA can be hastened with addition of TIPA, which attributes to the increased amount of FS and C-A-S-H gel in hydration products.

\section{Data Availability}

The data used to support the findings of this study are available from the corresponding author upon request.

\section{Conflicts of Interest}

The authors declare that there are no conflicts of interest regarding the publication of this paper.

\section{Acknowledgments}

Financial support from the National Key R\&D Program of China (2016YFC0701003-5) is gratefully acknowledged.

\section{References}

[1] X. Y. Lu, C. L. Li, and H. Zhang, "Relationship between the free and total chloride diffusivity in concrete," Cement and Concrete Research, vol. 30, no. 2, pp. 323-326, 2002.

[2] W. Li, B. Dong, Z. Yang et al., "Recent advances in intrinsic self-healing cementitious materials," Advanced Materials, vol. 30, no. 17, 2018.

[3] X. Shi, N. Xie, K. Fortune, and J. Gong, "Durability of steel reinforced concrete in chloride environments: an overview," Construction and Building Materials, vol. 30, pp. 125-138, 2012.

[4] B. Martın-Pereza, H. Zibarab, R. D. Hootonb, and M. D. A. Thomas, "A study of the effect of chloride binding on service life predictions," Cement and Concrete Research, vol. 30, no. 8, pp. 1215-1223, 2000.

[5] J. Xiao, C. Qiang, A. Nanni, and K. Zhang, "Use of sea-sand and seawater in concrete construction: current status and future opportunities," Construction and Building Materials, vol. 155, pp. 1101-1111, 2017.
[6] F. Zou, H. Tan, Y. Guo, B. Ma, X. He, and Y. Zhou, "Effect of sodium gluconate on dispersion of polycarboxylate superplasticizer with different grafting density in side chain," Journal of Industrial and Engineering Chemistry, vol. 55, pp. 91-100, 2017.

[7] H. Tan, B. Gu, Y. Guo et al., "Improvement in compatibility of polycarboxylate superplasticizer with poor-quality aggregate containing montmorillonite by incorporating polymeric ferric sulfate," Construction and Building Materials, vol. 162, pp. 566-575, 2018.

[8] B. Ma, Y. Peng, H. Tan et al., "Effect of hydroxypropyl-methyl cellulose ether on rheology of cement paste plasticized by polycarboxylate superplasticizer," Construction and Building Materials, vol. 160, pp. 341-350, 2018.

[9] F. P. Glasser, A. Kindness, and S. A. Stronach, "Stability and solubility relationships in AFm phases," Cement and Concrete Research, vol. 29, no. 6, pp. 861-866, 1999.

[10] S. Yoon, J. Ha, S. R. Chae et al., "Phase changes of monosulfoaluminate in $\mathrm{NaCl}$ aqueous solution," Materials, vol. 9, no. 5 , p. 401, 2016.

[11] E. P. Nielsen, D. Herfort, and M. R. Geiker, "Binding of chloride and alkalis in Portland cement systems," Cement and Concrete Research, vol. 35, no. 1, pp. 117-123, 2005.

[12] M. Marinescu and J. Brouwers, "Chloride binding related to hydration products part I: ordinary Portland cement," Advances in Modeling Concrete Service Life, vol. 3, pp. 125-131, 2012.

[13] D. M. Burgos, Á. Guzmán, N. Torres, and S. Delvasto, "Chloride ion resistance of self-compacting concretes incorporating volcanic materials," Construction and Building Materials, vol. 156, pp. 565-573, 2017.

[14] J. Geng, D. Easterbrook, L. Y. Li, and L. W. Mo, "The stability of bound chlorides in cement paste with sulfate attack," Cement and Concrete Research, vol. 68, pp. 211-222, 2015.

[15] C. Alonsoa, C. Andradea, M. Castellotea, and P. Castrob, "Chloride threshold values to depassivate reinforcing bars embedded in a standardized OPC mortar," Cement and Concrete Research, vol. 30, no. 7, pp. 1047-1055, 2000.

[16] H. Justnes, "A review of chloride binding in cementitious systems," Nordic Concrete Research, vol. 21, pp. 1-6, 1998.

[17] Y. Guo, B. Ma, Z. Zhi et al., "Effect of polyacrylic acid emulsion on fluidity of cement paste," Colloids and Surfaces A: Physicochemical and Engineering Aspects, vol. 535, pp. 139148, 2017.

[18] R. K. Dhir, M. A. K. El-Mohr, and T. D. Dyer, "Developing chloride resisting concrete using PFA," Cement and Concrete Research, vol. 17, no. 11, pp. 1633-1639, 1997.

[19] H. Zibara, R. D. Hooton, M. D. A. Thomas, and K. Stanish, "Influence of the $\mathrm{C} / \mathrm{S}$ and $\mathrm{C} / \mathrm{A}$ ratios of hydration products on the chloride ion binding capacity of lime-SF and lime-MK mixtures," Cement and Concrete Research, vol. 38, no. 3, pp. 422-426, 2008.

[20] X. Gong, Y. Wang, and T. Kuang, "ZIF-8-based membranes for carbon dioxide capture and separation," ACS Sustainable Chemistry and Engineering, vol. 5, no. 12, pp. 11204-11214, 2017.

[21] J. Paya, J. Monzo, M. V. Borrachero, and E. Peris-Mora, "Mechanical treatment of fly ashes. Part I: physico-chemical characterization of ground fly ashes," Cement and Concrete Research, vol. 25, no. 7, pp. 1469-1479, 1995.

[22] A. Dakhane, S. Tweedley, S. Kailas, R. Marzke, and N. Neithalath, "Mechanical and microstructural characterization of alkali sulfate activated high volume fly ash binders," Materials and Design, vol. 122, pp. 236-246, 2017. 
[23] J. Mei, H. Tan, H. Li et al., "Effect of sodium sulfate and nano$\mathrm{SiO}_{2}$ on hydration and microstructure of cementitious materials containing high volume fly ash under steam curing," Construction and Building Materials, vol. 163, pp. 812-825, 2018.

[24] E. Gartner and D. Myers, "Influence of tertiary alkanolamines on Portland cement hydration," Journal of the American Ceramic Society, vol. 76, no. 6, pp. 1521-1530, 1993.

[25] Z. Xu, W. Li, J. Sun et al., "Research on cement hydration and hardening with different alkanolamines," Construction and Building Materials, vol. 141, pp. 296-306, 2017.

[26] H. Huang, X.-R. Li, and X.-D. Shen, "Hydration of ternary cement in the presence of triisopropanolamine," Construction and Building Materials, vol. 111, pp. 513-521, 2016.

[27] B. Zhang, H. Tan, B. Ma et al., "Preparation and application of fine-grinded cement in cement-based material," Construction and Building Materials, vol. 157, pp. 34-41, 2017.

[28] JGJ/T 322-2013, Technical Specification for Test of Chloride Ion Content in Concrete, China Architecture and Building Press, Beijing, China, 2013, in Chinese.

[29] U. A. Birnin-Yauri and F. P. Glasser, "Friedel's salt, $\mathrm{Ca}_{2} \mathrm{Al}$ $(\mathrm{OH}) 6(\mathrm{Cl}, \mathrm{OH}) \cdot 2 \mathrm{H}_{2} \mathrm{O}$ : its solid solutions and their role in chloride binding," Cement and Concrete Research, vol. 28, no. 12, pp. 1713-1723, 1998.

[30] C. A. Love, I. G. Richardson, and A. R. Brough, "Composition and structure of C-S-H in white Portland cement-20\% metakaolin pastes hydrated at $25^{\circ} \mathrm{C}$," Cement and Concrete Research, vol. 37, no. 2, pp. 109-117, 2007.

[31] L. Wang and Z. He, "Quantitative of fly ash-cement hydration by 29Si MAS NMR," Journal of the Chinese Ceramic Society, vol. 38, no. 11, pp. 2212-2216, 2010.

[32] Z. Wang, J. Wu, P. Zhao et al., "Improving cracking resistance of cement mortar by thermo-sensitive poly $\mathrm{N}$-isopropyl acrylamide (PNIPAM) gels," Journal of Cleaner Production, vol. 176, pp. 1292-1303, 2018.

[33] M. D. A. Thomas, R. D. Hooton, A. Scott, and H. Zibara, "The effect of supplementary cementitious materials on chloride binding in hardened cement paste," Cement and Concrete Research, vol. 42, no. 1, pp. 1-7, 2012.

[34] Z. Shi, M. R. Geiker, B. Lothenbach et al., "Friedel's salt profiles from thermogravimetric analysis and thermodynamic modelling of Portland cement-based mortars exposed to sodium chloride solution," Cement and Concrete Composites, vol. 78, pp. 73-83, 2017.

[35] J.-P. Rapina, G. Renaudinb, E. Elkaimc, and M. Francoisa, "Structural transition of Friedel's salt $3 \mathrm{CaO} \cdot \mathrm{Al}_{2} \mathrm{O}_{3} \cdot \mathrm{CaCl}_{2} \cdot 10 \mathrm{H}_{2} \mathrm{O}$ studied by synchrotron powder diffraction," Cement and Concrete Research, vol. 32, pp. 513-519, 2002.

[36] H. Taylor, Cement Chemistry, Thomas Telford, London, UK, 1997.

[37] Z. Shi, C. Shi, H. Liu, and P. Li, "Effects of triisopropanol amine, sodium chloride and limestone on the compressive strength and hydration of Portland cement," Construction and Building Materials, vol. 125, pp. 210-218, 2016.

[38] Y. Wang and X. Gong, "Special oleophobic and hydrophilic surfaces: approaches, mechanisms, and applications," Journal of Materials Chemistry A, vol. 5, no. 8, pp. 3759-3773, 2017.

[39] A. Ipavec, T. Vuk, R. Gabrovšek, and V. Kaučič, "Chloride binding into hydrated blended cements: the influence of limestone and alkalinity," Cement and Concrete Research, vol. 48, pp. 74-85, 2013.

[40] H. Huang, X. Shen, and J. Zheng, "Modeling, analysis of interaction effects of several chemical additives on the strength development of silicate cement," Construction and Building Materials, vol. 24, no. 10, pp. 1937-1943, 2010.

[41] S. Ma, W. Li, S. Zhang, Y. Hu, and X. Shen, "Study on the hydration and microstructure of Portland cement containing diethanol-isopropanolamine," Cement and Concrete Research, vol. 67, pp. 122-130, 2015. 


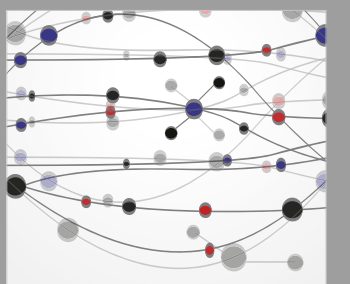

The Scientific World Journal
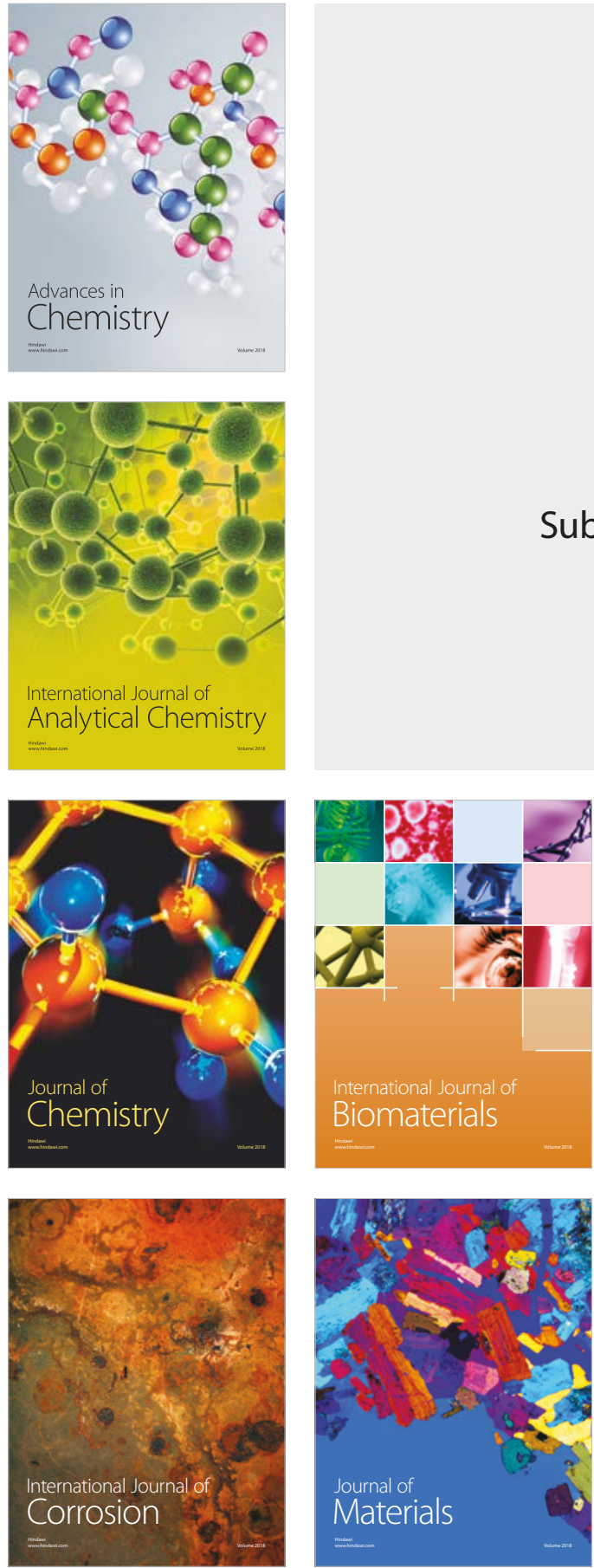

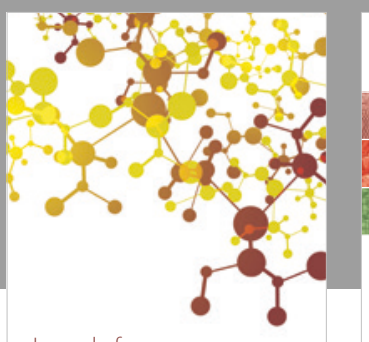

Journal of

Applied Chemistry
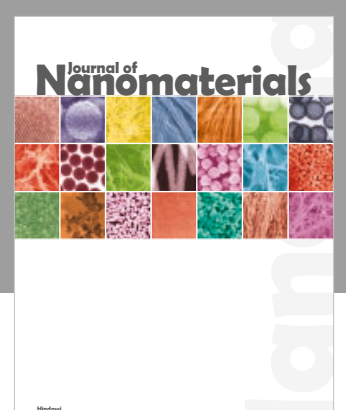

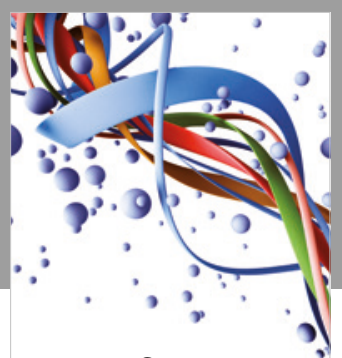

Scientifica

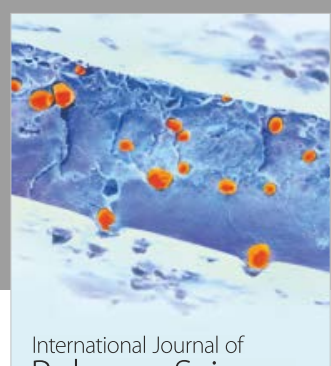

Polymer Science

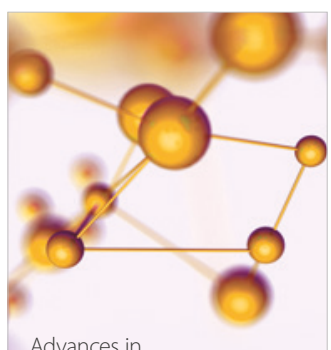

Physical Chemistry
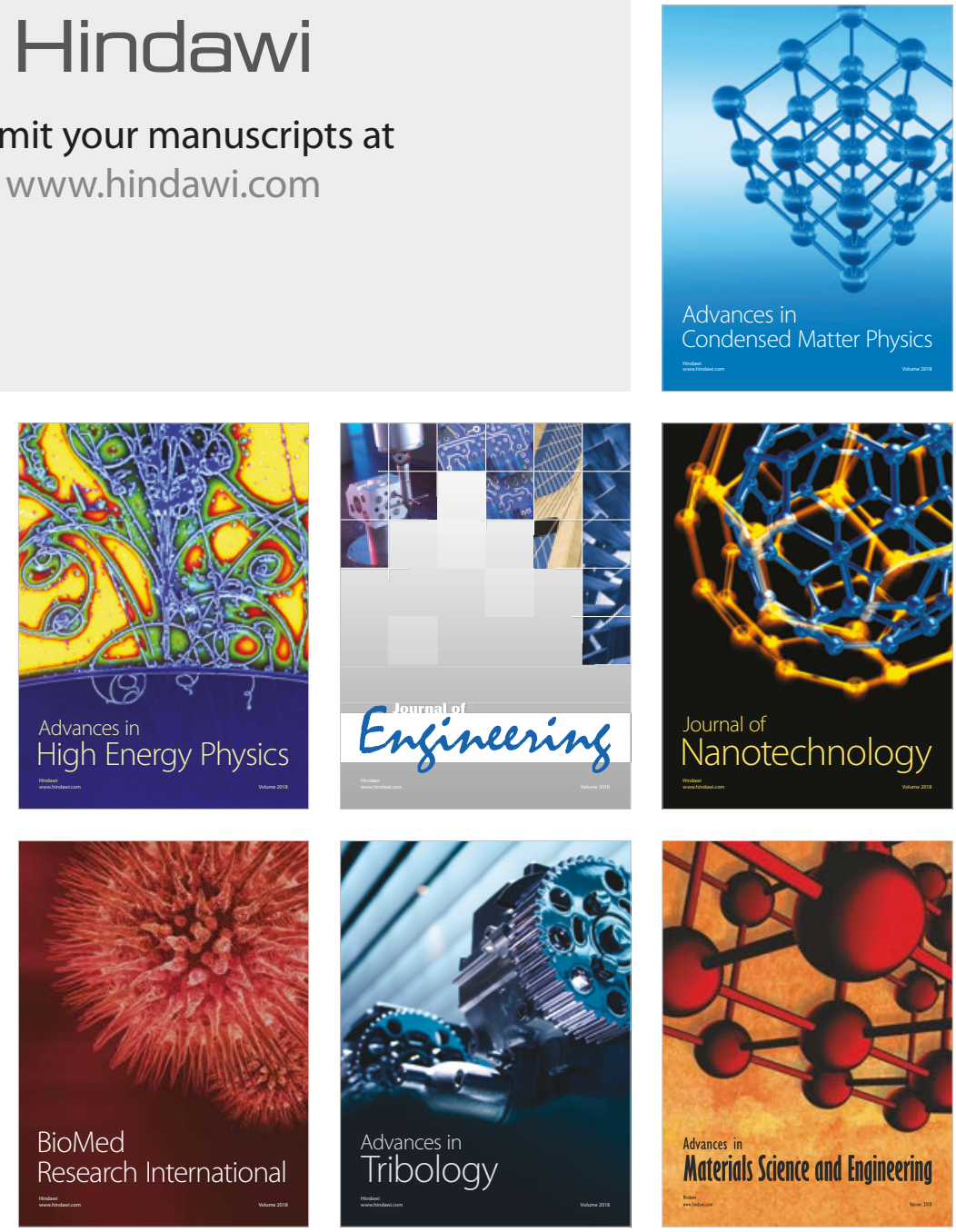